\title{
Effective High-Level Disinfection of Cystoscopes: Is Perfusion of Channels Required?
}

In the United States, more than 4 million cystoscopies are performed each year. Cystoscopy is a diagnostic procedure that uses an endoscope specially designed to examine the bladder, lower urinary tract, and prostate gland or is used to collect urine samples, perform biopsies, or remove small stones. A flexible or rigid scope can be used to carry out the procedure. Because the procedure involves a medical device in contact with the patient's mucous membranes, it is considered a semicritical device that must, at a minimum, undergo highlevel disinfection. Failure to properly high-level disinfect or sterilize equipment can lead to transmission of infection. ${ }^{1,2}$

The goal of this study was to examine the effectiveness of complete immersion of a channeled endoscope versus immersion plus perfusion of the high-level disinfectant into the channel of the endoscope.

This study was conducted at the University of North Carolina (UNC) Hospitals, an 840-bed academic medical center. A flexible fiberscope (Model 7305, Richard Wolfe, 
TAвLE 1. Effectiveness of Glutaraldehyde Disinfection with Cystoscopes when Actively Perfused and Not Perfused with a High-Level Disinfectant

\begin{tabular}{lcccc}
\hline & $\begin{array}{c}\text { VRE Inoculum before } \\
\text { HLD (Glutaraldehyde), } \\
\text { CFU/mL }\end{array}$ & $\begin{array}{c}\text { VRE Contamination } \\
\text { after HLD, CFU/mL }\end{array}$ & $\begin{array}{c}\text { Kneumoniae (CRE) Inoculum } \\
\text { before HLD (Glutaraldehyde), } \\
\text { CFU/mL }\end{array}$ & $\begin{array}{c}\text { K. pneumoniae (CRE) } \\
\text { Contamination after HLD, } \\
\text { CFU/mL }\end{array}$ \\
\hline "Passive" HLD (immersed, & $3.6 \times 10^{8}$ & $5.0 \times 10^{7}$ & $3.2 \times 10^{8}$ & $3.1 \times 10^{8}$ \\
not perfused) & $2.9 \times 10^{8}$ & $1.0 \times 10^{8}$ & $1.8 \times 10^{9}$ & $4.6 \times 10^{8}$ \\
"Active" HLD (perfused) & $1.1 \times 10^{8}$ & $6.8 \times 10^{7}$ & $4.1 \times 10^{8}$ & $1.0 \times 10^{8}$ \\
& $8.4 \times 10^{7}$ & $1 \mathrm{CFU}$ & $3.0 \times 10^{8}$ & 0 \\
& $1.5 \times 10^{8}$ & 0 & $9.2 \times 10^{8}$ & 0 \\
& $2.8 \times 10^{8}$ & 0 & $8.4 \times 10^{8}$ & 0 \\
\hline
\end{tabular}

HLD, high-level disinfectant; CRE-carbapenem-resistant Enterobacteriaceae

${ }^{\mathrm{a}}$ Control inoculum after $24 \mathrm{~h}$ without disinfection, VRE $=1.34 \times 10^{8} \mathrm{CFU} / \mathrm{mL} ;$ Klebsiella pneumoniae $(\mathrm{CRE})=4.9 \times 10^{8} \mathrm{CFU} / \mathrm{mL}$.

Vernon Hills, Indiana), which has an internal diameter of $2.5 \mathrm{~mm}$ and $400 \mathrm{~mm}$ working length, was used in this study. The cystoscope channel was inoculated with $1 \mathrm{~mL}$ of a 0.5 McFarland test organism suspension and allowed to dry in a biological safety cabinet in a horizontal position for 2 hours. After 2 hours, the inoculating suspension was drained and the scope was allowed to air dry in a vertical position for 24 hours. After 24 hours, the endoscope was placed in an immersion bath of $2.4 \%$ glutaraldehyde (Cidex, Advanced Sterilization Products) for 20 minutes at room temperature. After 20 minutes, the scope was removed from the bath, and the lumen of the scope was flushed and brushed with $15 \mathrm{~mL}$ of a neutralizer (ie, $3 \%$ glycine with $0.1 \%$ Tween 80 ). After flushing and brushing, serial dilutions of the "flush" solution were made when significant levels of contamination were expected. These serial dilutions were plated onto sheep blood agar plates (BBL, Becton Dickinson Company, Sparks, MD) in duplicate and incubated at $35-37^{\circ} \mathrm{C}$ for 48 hours. After 48 hours, the plates were read and quantitated. When low-level contamination was expected, the solution was filtered through an analytical filter $(0.2 \mu \mathrm{m}$, Thermo Scientific, Waltham, MA), and the filter was then placed, aseptically, on sheep blood agar. After each run, the scope was sterilized using ethylene oxide (3M SteriVac, St. Paul, MN). The experiments were performed in triplicate for each test organism and exposure condition. Two cystoscopies were performed as controls for which highlevel disinfection was not conducted. The "passive" high-level disinfection procedure involved fully immersing the cystoscope into a bath of $2.4 \%$ glutaraldehyde for 20 minutes at room temperature, but no forced flow of the high-level disinfectant into the endoscope channel was performed. A minimum effective concentration of glutaraldehyde was determined before each use (Comply Cold Sterilog, 3M Health Care, St. Paul, MN). The "active" high-level disinfection was conducted by attaching a luer-lock syringe to the port and flushing glutaraldehyde back and forth through the port/ syringe until there were no bubbles in the interior lumen of the scope or syringe. The syringe was left on the port until disinfection was complete. The test organisms were vancomycin-resistant Enterococcus or VRE (ATCC \#51299) and a carbapenem-resistant Enteriobacteriaceae (CRE), Klebsiella pneumoniae (clinical isolate).

Our results demonstrated that disinfection (ie, a reduction in bacterial load of greater than $7 \log _{10}$ CFU) did not occur unless the channel was actively perfused with the glutaraldehyde (Table 1). In fact, failure to perfuse the channel led to only minimal, if any, reduction in bacterial contamination. However, complete inactivation of $10^{8} \mathrm{CFU}$ of both VRE and CRE was achieved when the channel was actively perfused. It appears that no high-level disinfectant entered the channel unless it was actively perfused because the level of microbial contamination was not reduced by immersion. This occurs because the air pressure in the channel is stronger than the fluid pressure at the fluid-air interface. Recommendations are provided for cystoscope high-level disinfection in Table 2 and include actively perfusing the device while immersed in the high-level disinfectant.

Endoscopes are valuable diagnostic and therapeutic tools; however; many outbreaks have been linked to contaminated medical devices such as gastrointestinal endoscopes. ${ }^{1-3}$ Cystoscopes have also been implicated as the source of infection to multiple patients when incorrect disinfection methods were identified. ${ }^{4}$ This may, in part, be related to the lack of awareness of recommendations specifically for disinfecting cystoscopes ${ }^{5}$ or failing to follow the manufacturer's instructions, which specify perfusing the lumen using a high-level disinfectant. Unfortunately, some cystoscope reprocessing recommendations published in the literature are incorrect. For example, authors have recommended complete immersion of the cystoscope into the high-level disinfectant but did not mention perfusion of the high-level disinfectant into the channel. ${ }^{4}$ We suggest following our recommendations (Table 2) and those of the American Urological Association ${ }^{5}$ until evidence-based guidelines have been published.

\section{ACKNOWLEDGMENTS}

We thank Dale J. Payne PhD for his assistance.

Financial support. No financial support was provided relevant to this article. 


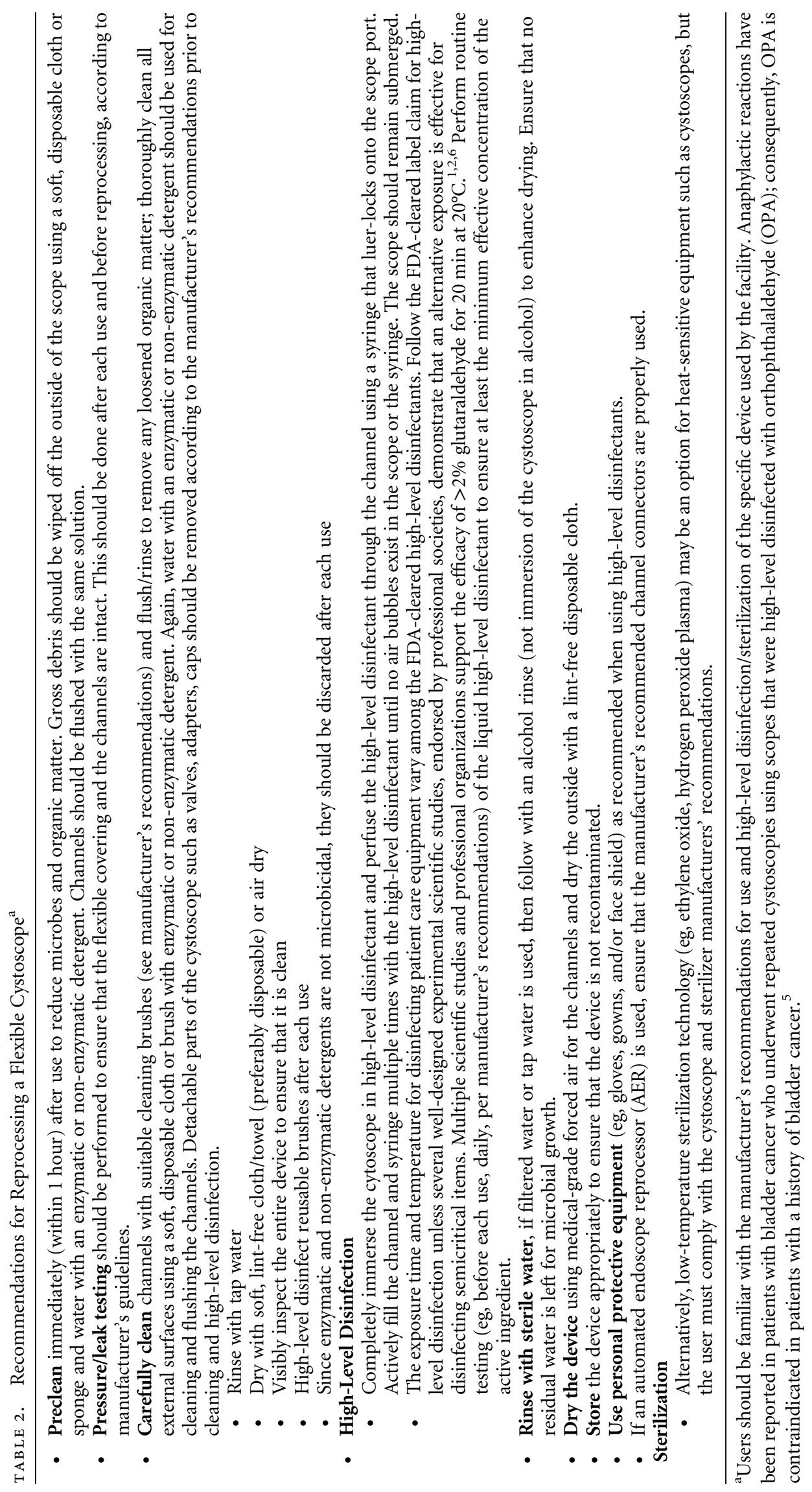


Potential conflicts of interest. Dr. Rutala is a consultant for Clorox and has received honoraria from $3 \mathrm{M}$. Dr. Weber is a consultant for Clorox.

\section{William A. Rutala, PhD, MPH, CIC; ${ }^{1,2}$ Maria F. Gergen, MT (ASCP); ${ }^{1}$ Judie Bringhurst, MSN, RN, CIC; ${ }^{1}$ David J. Weber, MD, MPH ${ }^{1,2}$}

Affiliations: 1. Hospital Epidemiology, University of North Carolina Health Care, Chapel Hill, North Carolina; 2. Division of Infectious Diseases, UNC School of Medicine, Chapel Hill, North Carolina.

Address correspondence to William A. Rutala, PhD, MPH, Director, Hospital Epidemiology, Occupational Health, and Safety Program; Room 1001 West Wing, UNC Health Care, Chapel Hill, NC 27514 (brutala@unch. unc.edu).

Received August 3, 2015; accepted September 20, 2015; electronically published November 10, 2015

Infect. Control Hosp. Epidemiol. 2016;37(2):228-231

(C) 2015 by The Society for Healthcare Epidemiology of America. All rights reserved. 0899-823X/2016/3702-0019. DOI: 10.1017/ice.2015.266

\section{REFERENCES}

1. Rutala WA, Weber DJ, Healthcare Infection Control Practices Advisory Committee. Guideline for disinfection and sterilization in healthcare facilities, 2008. Centers for Disease Control and Prevention website. http://www.cdc.gov/hicpac/pdf/guidelines/ Disinfection_Nov_2008.pdf. Accessed September 10, 2015.

2. Rutala WA, Weber DJ. Selection and use of disinfectants in healthcare. In Mayhall CG ed. Hospital Epidemiology and Infection Control, 4th ed. Philadelphia: Wolters Kluwer/Lippincott Williams \& Wilkins, 2012.

3. Kovaleva J, Peters FTM, van der Mei HC, Degener JE. Transmission of infection by flexible gastrointestinal endoscopy and bronchoscopy. Clin Reviews Microbiol 2013;26:231-253.

4. Wendelboe AM, Baumbach J, Blossom DB, Frank P, Srinivasan A Sewell CM. Outbreak of cystoscopy-related infections with Pseudomonas aeruginosa: New Mexico, 2007. J Urology 2008;180:588-592.

5. Clemens JQ, Goldman H, Senese V, Bertsch J. Joint American Urological Association and Society of Urological Nurses and Associates white paper on reprocessing of flexible cystoscopies. American Urological Association website. https://www.auanet. org/common/pdf/education/clinical-guidance/Cystoscopy-WP.pdf. Accessed July 29, 2015.

6. Petersen BT, Chennat J, Cohen J, Cotton PB, Greenwald DA, Kowalski TE, Krinsky ML, Park WG, Pike IM, Romagnuolo J, Rutala WA. Multisociety guideline on reprocessing flexible GI endoscopes, 2011. Infect Control Hosp Epidemiol 2011;32:527-537. 